\title{
THE RESEARCH ON AGEING OF GLYCOL-BASED BRAKE FLUIDS OF VEHICLES IN OPERATION
}

\author{
Jacek Cabann ${ }^{1}$, Paweł Droździel ${ }^{2}$, Ján Vrábel ${ }^{3}$, Branislav Šarkan³ \\ Andrzej Marczuk', Leszek Krzywonos², Iwona Rybicka²
}
1 University of Life Sciences in Lublin, Faculty of Production Engineering, Department of Transporting and Agricultural Machinery, 28 Głęboka Str., 20-612 Lublin, Poland, e-mail: jacek.caban@up.lublin.pl, adrzej. marczuk@up.lublin.pl
2 Lublin University of Technology, Faculty of Mechanical Engineering, 36 Nadbystrzycka Str. 20-618 Lublin, Poland,,e-mail: p.drozdziel@pollub.pl, I.krzywonos@pollub.pl, i.rybicka@pollub.pl
3 University of Žilina, Faculty of Operation and Economics of Transport and Communications, Univerzitna 1, 010 26, Žilina, Slovakia, e-mail: jan.vrabel@fpedas.uniza.sk

Received: 2016.08.30

Accepted: 2016.10.08

Published: 2016.12.01

\begin{abstract}
The road safety depends on many factors, including the efficiency of the technical system and the disposal of the driver of the vehicle. As wear of most of the vehicle assemblies threatened only with a breakdown, excessive wear of the braking system components may pose a risk of a traffic accident. The article presents a study on the quality of the brake fluid conductivity as a function of temperature and water content conducted for a selected group of vehicles. This group of vehicles was characterized by different production date and had a different of vehicle mileage. We presented the methodology of statistical analysis of the quality of brake fluid tests in selected 38 passenger vehicles in operation.
\end{abstract}

Keywords: braking system, fluids ageing, operational, road safety, wear.

\section{INTRODUCTION}

Technical development has contributed to social development and growth of consumer requirements associated also with the use of means of transport. During the past decades, rapid growth of traffic volume, especially motorized road mobility, has resulted in continuously increasing safety problems [26]. Europe, recognized as one of the safest road traffic regions in the world, also suffers from the road crash problems [26]. Vehicle congestion and high risk of accidents result in disapointment of many drivers and public transport users, causing psychological tension and increasing the accident rate [13]. In order to improve safety the efficiency and reliability of vehicle safety systems are systematically increased and more perfect consumables are used. For use in industry and automotive lubrication are the most important synthetic hydrocarbons (particularly polyalphaolefins (PAOs)), carboxylic acid esters (complex esters and polyesters) and polyalkylene glycols (PAG) [1].

Many research works were devoted to issues concerning the maintenance of the reliability of vehicles as one of the features being favourable for safety. Michalski and Wierzbicki [20] conducted the analysis of degradation of different systems in vehicles being already in service. Gardyński and Lonkwic [9] investigated physical and chemical properties of polymer materials used in transportation. Marczuk et all [18] presented the problem of degradation of means of transport and use of components from end-of-life vehicles. In the literature concerning road transport issues can be found many scientific works on the state 
of road safety in Poland [2] and Europe [8, 13, $23,26]$. Skrúcaný and others $[27,28]$ investigated dangers to traffic related to heavy goods vehicle traffic under different loads and in varying conditions of operating as well as during braking process. In order to increase vehicle transport safety complex mechatronical systems such as passive and active safety systems are implemented in all new vehicles. One of the most important safety systems in the vehicle is braking system, which has a decisive impact on the safety level of an active car. In the literature, there is a lot of work about the friction elements of the braking systems $[11,14,22,24,25,30]$ but only few concerning the quality of brake fluid $[3,5,17]$.

Requirements for brake systems of cars were formulated in Regulations of 13 UN Economic Commission for Europe (ECE) [29]. These requirements relate to braking motion stability of the vehicle during braking and reliability of braking system. The braking performance is expressed by braking distance being influenced by technical condition of the braking system and by pressure in tires [4]. The braking distance of a vehicle also depends on several factors having an impact on tire grip, such as weather conditions (rain, fog, lighting conditions), geographic conditions (e.g. slope of the land), speed, quality and type of tire $[10,23]$, as well as the braking system technical condition. As is clear from the KRBRD Report [21] concerning the faults occurring in the vehicle safety systems, up to $22.5 \%$ of the causes of traffic events is caused by a malfunction of the braking system. But the one who primarily determines the state of security is a human being - the driver. Jun [16] examined patterns of speeding, acceleration and braking to predict crash involvement using data collected with an in-vehicle device incorporating GPS and onboard diagnostics (OBD). The objective here was to identify behaviours and their relationship to crash risk. These (individual) behavioural measures correctly predicted $68 \%$ of crash-involved drivers (26 drivers) and $87 \%$ of non-crash-involved drivers (141 drivers) [7].

The brake system is a safety critical component necessary for the safe operation of the vehicle [14]. Braking systems have drastically improved since the arrival of ABS (anti-lock braking systems), as has driving control through the development of 4WD (Four-Wheel Drive Systems) and TCL (Traction Control Systems) [24]. ABS is implemented in automobiles to ensure optimal vehicle control and minimal stopping distances during hard or emergency braking with the contribution to vehicle safety [6]. The braking performance of the ABS depends on control logics to overcome the time-varying nature of the braking dynamics and many uncertain parameters such as environments, road and friction coefficient [6]. Fault diagnosis is an important process in preventive maintenance of hydraulic brakes [11]. The faults in a hydraulic brake system of an automobile are not fairly noticeable [14]. Some warning signs that there is something wrong with brakes include a performing or squeaking noise [14]. This identification is only friction brake system, the brake fluid may not be assessed in this way. If faulty brakes are used, the vehicle cannot be stopped within a reasonable distance. Brake fault may also be the cause of vehicle moving on unintentional track. Early detection of the defects, therefore, is crucial to prevent the system from malfunction that could cause damage to the entire system or accident [11].

The brake fluid is one of the most important elements of a breaking system, fulfilling many tasks [3]. The chemical composition of the brake fluid depends on the requirements for fluids concerning fluid chemical stability, higher operating temperature and ensuring adequate corrosion protection of brake components [5]. Brake fluids are typically a mixture of alkyl ethers, ethylene glycol $\left(\mathrm{C}_{2} \mathrm{H}_{6} \mathrm{O}_{2}\right)$, propylene glycol $\left(\mathrm{C}_{3} \mathrm{H}_{8} \mathrm{O}_{2}\right)$, boronic esters and polypropylene glycols with upgrading additives.

Technical condition of the brake system has a significant impact on the course of changes in the value of deceleration both in the rise of delay phase and after reaching the maximum values. To evaluate the technical condition of the brake system was adopted the braking efficiency rate expressed as a percentage and the difference between the values of braking forces at the wheels on the same axle. However, when assessing the technical condition of the car in terms of safety of the braking maneuver, taking into account the calculated value of the index of effectiveness can be insufficient. The braking process is influenced by: the condition of the tires, the condition of the suspension system of the vehicle, the state of the road surface and the quality of brake fluid. This last factor, both in workshop and research practice, is often an overlooked factor, despite the fact that it has a major impact on road safety.

The parts of hydraulic brake system components are subject to wear. In the scientific works 
much attention is devoted to such a common phenomenon as the aging of materials $[3,9,30]$, both from the point of view of knowledge of its mechanisms and assessment of the impact of aging on the properties of construction materials [15]. Phenomena associated with aging of polymer materials lead to the most irreversible changes of its properties and structure, and deterioration of the properties of the material [12]. Wear problem concerns not only components, but also working fluid or brake fluid. Consumption is caused by the cooperation of the components of the system dependent on driving style and intensity of use of the vehicle. It is therefore strongly dependent on vehicle velocity and acceleration [19] braking, and driver behavior. The aim of the brake fluid is to transfer the pressure from the ABS pump (activated by the driver's foot with the participation of assisted system), to the brake cylinder moving friction component, in the form of brake pad (in disc brakes) or brake shoe (in drum brakes) to lead to slow down or stop the vehicle by friction.

For the smooth functioning of the main brake system are properties of brake fluid, and therefore the appropriate level of the brake fluid, its frequent checking and adding or replacing when the coolant quality parameters deteriorate. The working temperature of a braking system in normal drive may be in the range of $300^{\circ} \div 700^{\circ} \mathrm{C}$ [3]. The changing working conditions of the brake fluid in operation (absorption of moisture and the ageing processes) make the periodical change necessary [3].

All those phenomena cause the change of physical, chemical and rheological properties of the fluid but it is not sufficient to decide on that basis whether the fluid change is necessary [3]. Such information may be obtained from the boiling point measurements.

\section{RESEARCH METHODOLOGY}

Control tests of state parameters of brake fluid were carried out on a selected group of 38 vehicles. Vehicles were of different ages and with different vehicle mileage. The study was conducted in three stages, in annual increments for the same population of vehicles in operation. The study involved vehicles manufactured in 20002011. Changes in performance properties of the liquid were determined by measuring the water content and the value of brake fluid boiling point.
The water content determination tests were carried out using an electronic four-diode tester, and the measurement of the boiling point of the fluid was carried by 320 BFT brake fluid tester by ATE. Measurement in both cases was made by immersing the probe in the coolant expansion tank of the vehicle. BFT 320 ATE tester was characterized by the precision of the determination of the boiling point of all types of fluids used in the vehicles and based on glycol (DOT 3, DOT 4, DOT 5.1).

In the first stage of the study were tested 55 vehicles in order to determine operation parameters of brake fluids in the vehicles used. Then, from among of these vehicles were selected those which had the highest value of the brake fluid boiling point, and those in which the fluid was replaced. In the second and third stage of the test the measurements had been already carried on a constant group of 38 vehicles. Vehicle tests took place in the same period each year (NovemberDecember). The obtained results of measurements of the brake fluid were then analyzed by statistical tests using the Statistica ${ }^{\circledR}$ program.

The initial stage of the analysis of each transport system were univariate analysis (on one selected features of a statistical nature) [5]. They provided a starting point for further advanced analysis. The statistical tool to troubleshoot the classification in populations is the analysis of variance. The first step of this analysis is to assess compliance with the normal distribution. To test compliance with the normal distribution test was used Shapiro-Wilk's test. KołmogorowSmirnow's test was used to assess the types of one-dimensional distributions of statistical characteristics. Then testing the hypothesis of equality of the average values in comparable populations were carried out by means of rank order tests: Mann-Whitney U test (comparison of 2 trials) and Kruskal-Wallis test (comparison of more than 2 trials). This was due to a failure to comply with the requirements of the classical analysis of variance. In the analysis of multipartite tables was used Pearson's test and $\chi^{2}$ statistics of the maximum reliability. In assessing the correlation was used Pearson's linear correlation coefficient.

\section{TESTS RESULTS AND DISCUSSION}

The first carried out statistical analysis of compatibility assessment of empirical distribution with normal distribution showed (on the accepted in 
calculating the level of significance $p=0.05$ ), that for tests 1 and 2 the brake fluid boiling temperature histogram can be approximated by the normal distribution, but for the third test the distribution is not normal. Shapiro-Wilk test statistics for the first trial was $\mathrm{S}-\mathrm{W}=0.979$ at a significance level of $\mathrm{p}=$ 0.1378 , for the second trial S-W $=0.9690$ at a significance level of $\mathrm{p}=0.3675$ and for the third trial $\mathrm{S}-\mathrm{W}=0.9102$ at $\mathrm{p}=0.005$. Due to the fact that the
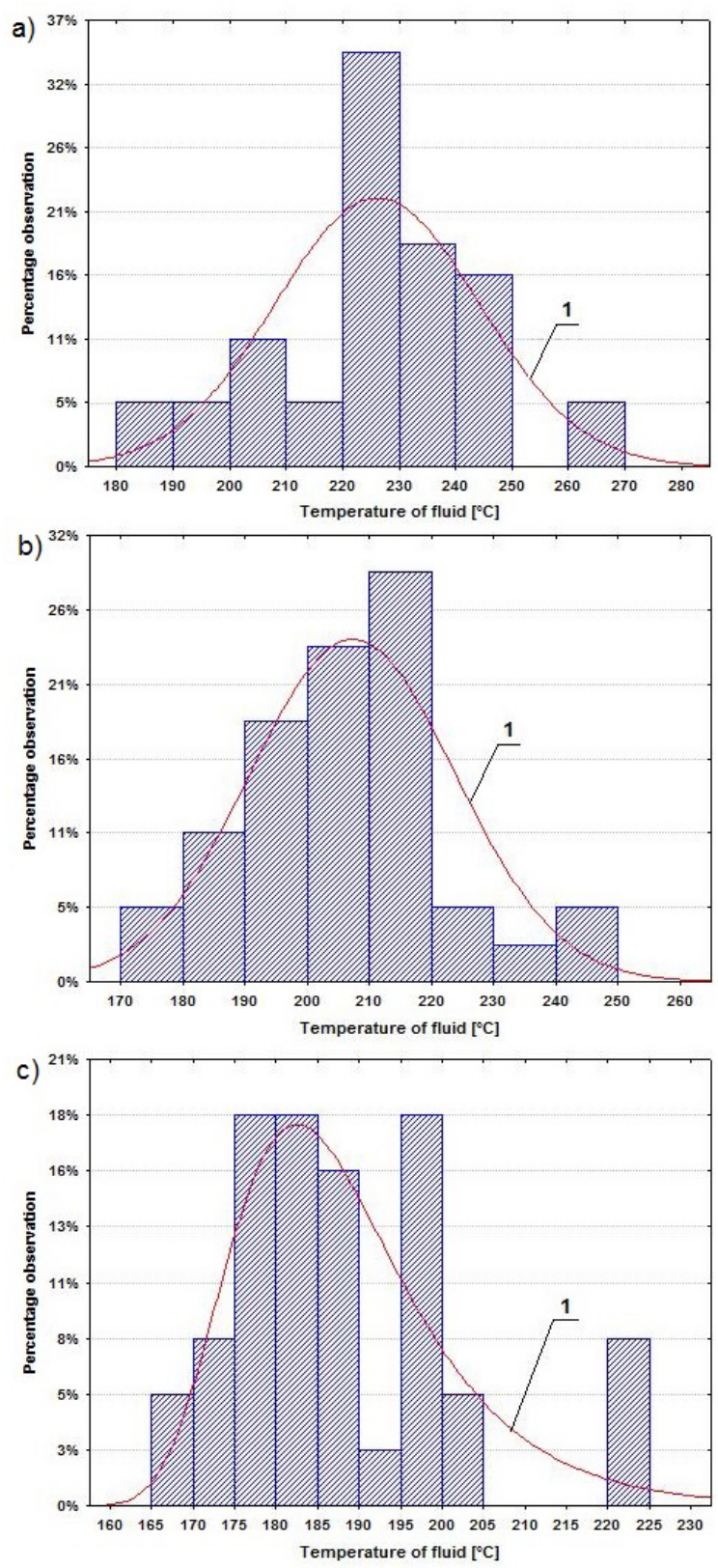

Fig. 1. The histogram of brake fluid boiling temperature in the test population of vehicles: 1 - normal distribution density function fitted to empirical data, a) with the parameters of position 225.89 and scale 18.01 at the $1^{\text {st }}$ trial, b) position 207.13 and scale 16.47 in a $2^{\text {nd }}$ trial, c) position 182.35 and scale 10.238 at the $3^{\text {rd }}$ trial data (for the third measurement of boiling temperature) did not comply with the match to a normal distribution, was used Kołmogorow-Smirnow's test to check how the theoretical distribution best approximates the results obtained. For distribution of extreme values the value K-S $=0.07112$ at a significance level of $p>0.20$. Figure 1 shows histograms of the obtained results.

In order to check whether the average boiling temperature of brake fluid differs significantly between successive tests of vehicles (due to failure to comply with the classical analysis of variance) for the investigated samples was used KruskalWallis rank order test. The results of the test K-W $=56.07361$ at a significance level of $p=0.00001$ indicate that there has been a significant decrease of the mean measured boiling temperature of brake fluid from $225.89^{\circ} \mathrm{C}$ to $188.47^{\circ} \mathrm{C}$. In Figure 2 is a chart showing the frame-whiskers presenting the dependencies of boiling temperature of brake fluid on the number of the test. Multiple comparisons test shows that there are statistically significant differences between the average values in the conducted trials: between trial 1 and 2 at a significance level of $p=0.0016$; trial 1 and 3 at a significance level of $\mathrm{p}=0.00001$; and between trial 2 and 3 at a significance level of $p=0.000276$.

The next statistical analysis, using contingency tables, had to check whether the percentage content of water in the brake fluid varies significantly between trials. The results of obtained calculations indicate $(\chi 2=44.5744$ at a significance level of $p=0.00001)$ that there are statistically significant differences in water content between the first and second measurement of the water content in the test brake fluids. The C Pearson's

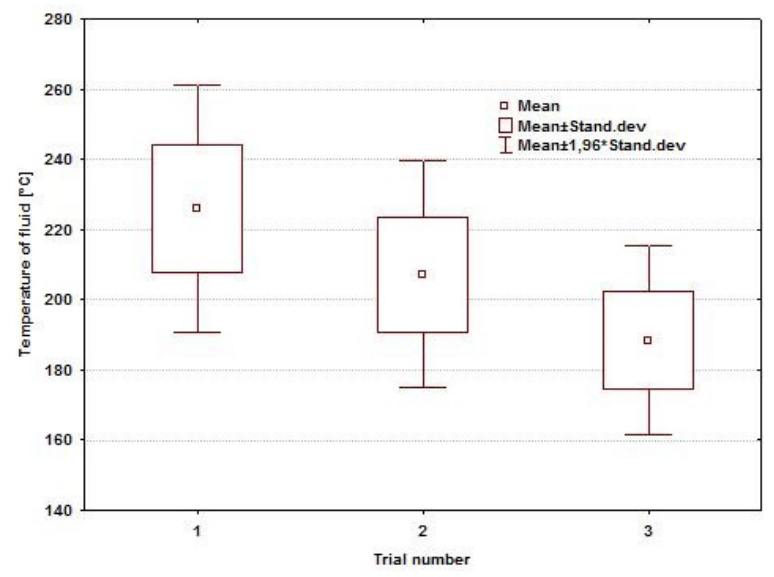

Fig. 2. A graph of dependencies of boiling temperature of brake fluid and the number of the vehicle test 


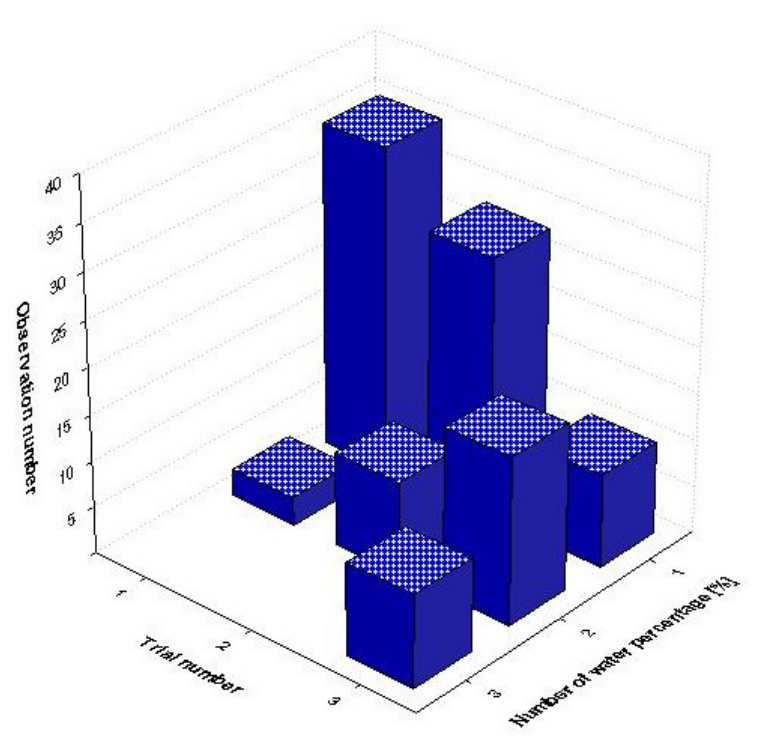

Fig. 3. The three-dimensional chart of the water content of the brake fluid in the test population of vehicles

contingency coefficient is $\mathrm{C}=0.530183$, which confirms an average-strong correlation between the number of the trial and percentage content of water in the brake fluid. Figure 3 shows the graphic interpretation of this correlation in the form of three-dimensional chart.

Figure 4a) shows the frame-whiskers graph, which illustrates the correlation of the kilometre mileage of the vehicle and the percentage content of water in the brake fluid between the trial 1 and 2. For this trial were no statistically significant differences. The Mann-Whitney $U$ test parameters amounted to $\mathrm{Z}=1.7133$ at $\mathrm{p}=0.08665$.

Figure $4 \mathrm{~b}$ ) shows the frame-whiskers graph, which illustrates the correlation of the kilometre mileage of the vehicle and the percentage content of water in the brake fluid between the trial 2 and 3 . The results of the test $\mathrm{K}-\mathrm{W}=8.02345$ at significance level of $p=0.0177$ indicate that there are statistically significant differences. Test multiple comparisons test showed that there is a statistically significant difference between $1 \%$ and $2 \%$ of the percentage of water $(p=0.0155)$ and the kilometre mileage of the vehicles between 2 and 3 measurement.

The results of the calculations indicate the lack of statistically significant differences between the average boiling temperature of the brake fluid $(\mathrm{Z}$ $=1.49213$ at the level of significance $p=0.1356$ ) and the percentage change in water content in the brake fluid between the trial 1 and 2. Figure 5a) shows the frame-whiskers graph, which illustrates the average temperature dependency of the boiling of the brake fluid and the change of the percentage of water content between the trial 1 and 2 .

The results of the calculations indicate the lack of statistically significant differences between the average boiling temperature of the brake fluid $(\mathrm{Z}=6.2575$ at the level of significance $p=0.0439)$ and the percentage change in water content in the brake fluid between the trial 2 and 3. The differences are statistically significant $(p=$ 0.00421 ) between the content of water of $1 \%$ and $2 \%$. Figure $5 \mathrm{~b}$ ) shows the frame-whiskers graph, which illustrates the average temperature dependency of the boiling temperature of the brake fluid and the change of the percentage of water content between the trial 2 and 3 .

An analysis of the correlations was carried out in order to check whether the change of the boiling temperature of the brake fluid depends on the ve-
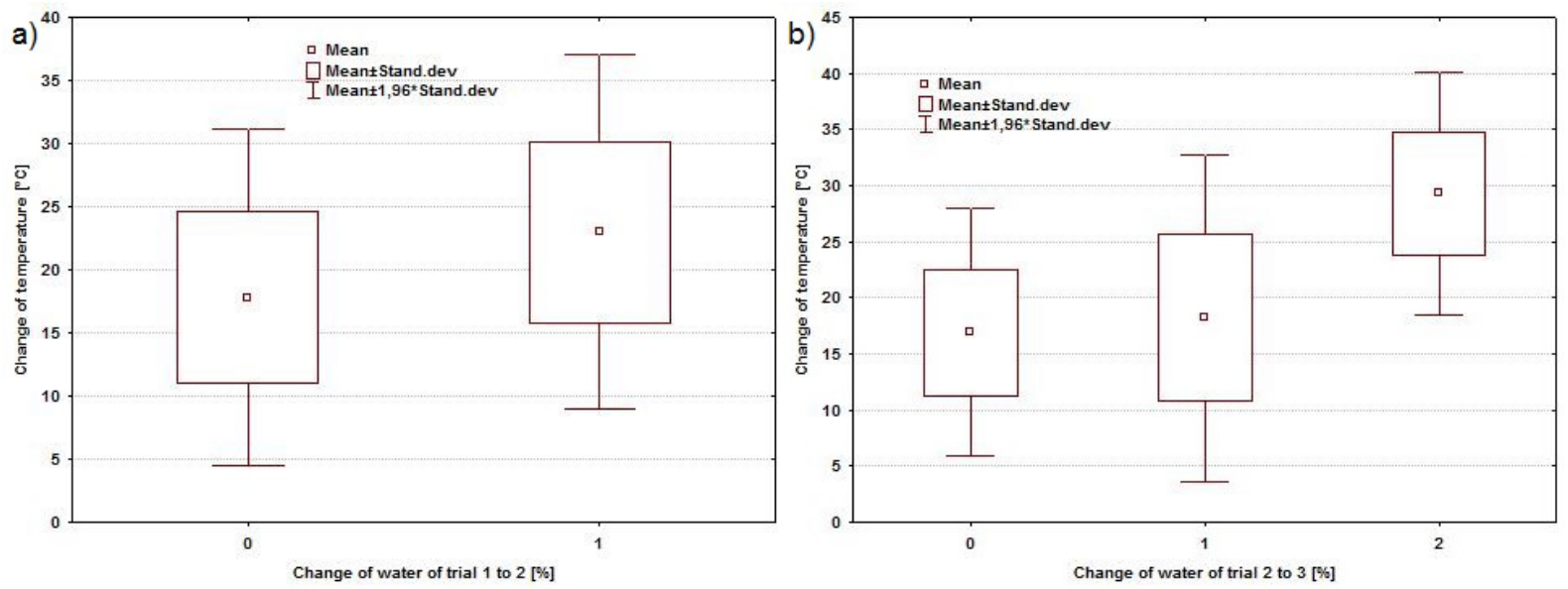

Fig. 4. The graph of dependencies content of the kilometre mileage of the vehicle and the change of the water content in the brake fluid a) between trial 1 and 2, b) trial 2 and 3 

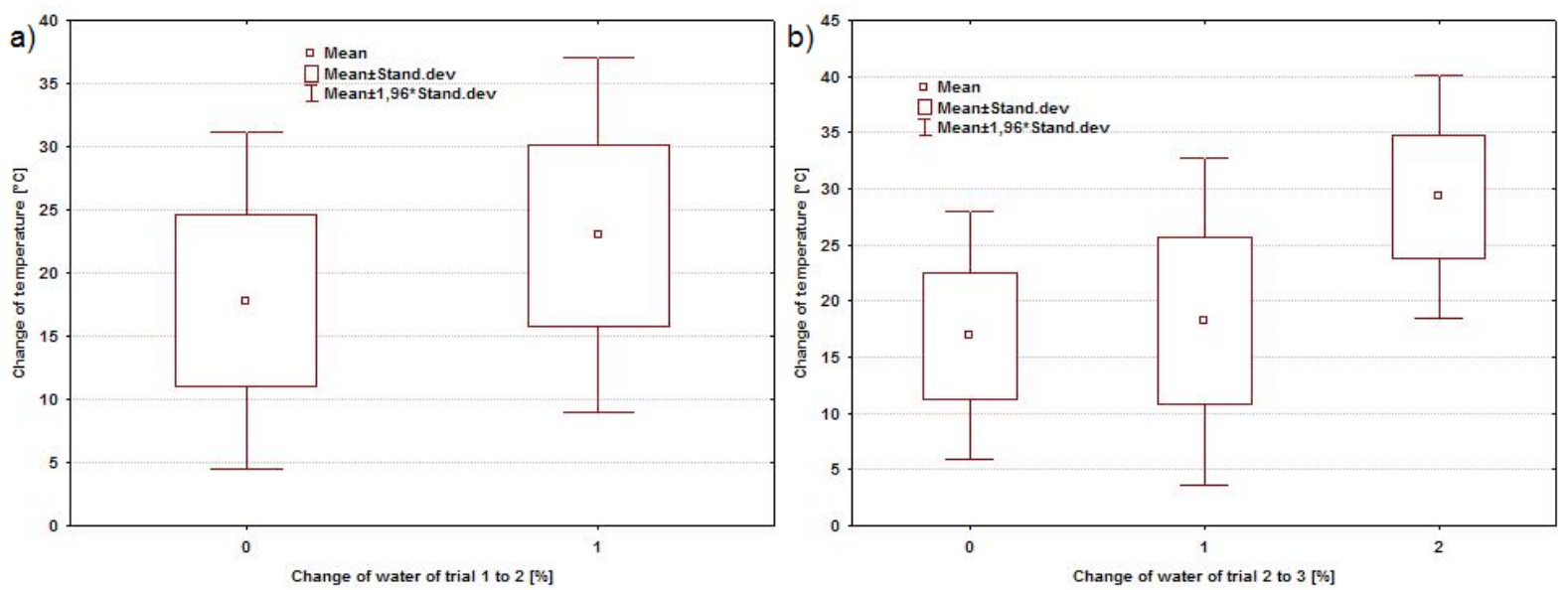

Fig. 5. The graph of boiling point of brake fluid and change of water content a) between trial 1 to 2 , b) trial 2 to 3

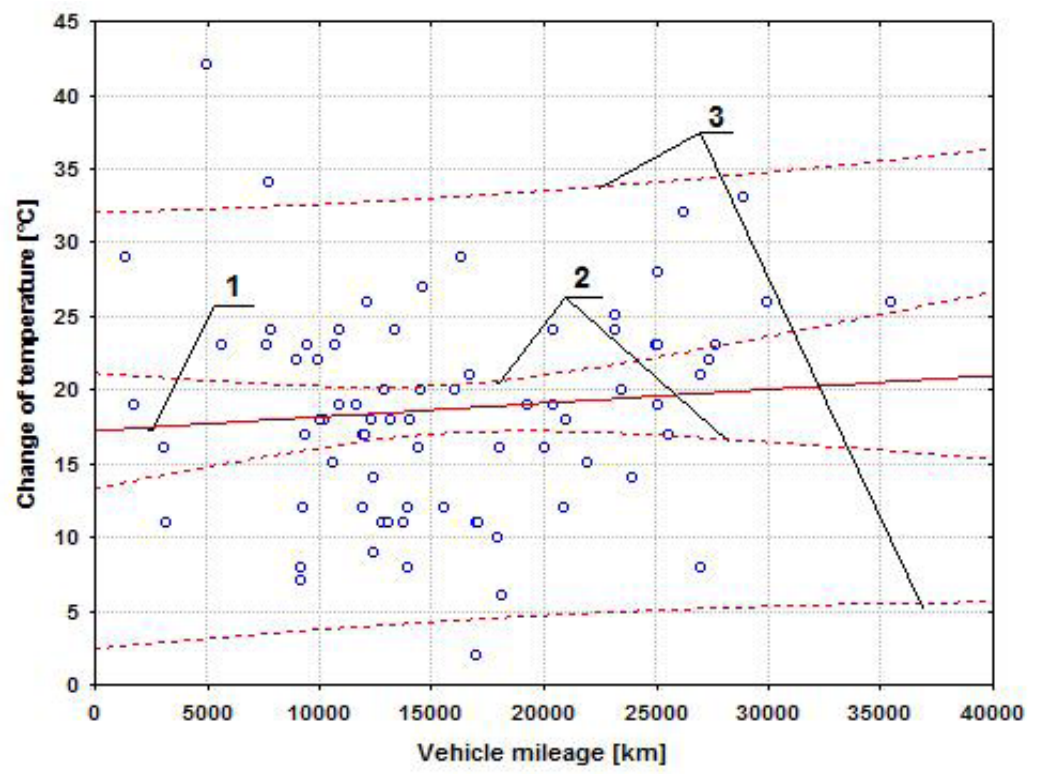

Fig. 6. Scatter plot of boiling point of brake fluid and vehicle mileage, 1 -regression line, 2 - confidence interval for the predicted mean observation, 3 - confidence interval for the predicted observation

hicle mileage between successive measurements. In Figure 6 is a chart of spread between the change of the boiling temperature of the brake fluid and the mileage of the vehicle between successive measurements. The value of the correlation coefficient $r=0.09566$ at significance level of $p=0.411$ pointed to the lack of statistically significant correlation for the boiling temperature of the brake fluid and the kilometre mileage of the vehicle.

\section{CONCLUSIONS}

The braking system has an essential role in the vehicle as one of the most important safety systems, is also of great importance for road safe- ty. As shown in the work the ageing of brake fluid is relatively quick, as already after three years its parameters are largely deteriorated. The studies carried out on the brake fluid have shown the usefulness of the methods used to determine changes in properties of fluids vehicle. It should be note that the boiling point of the brake fluid in the actuators (i.e. in the brake callipers) is much lower than measured in the coolant expansion tank.

The studies have shown that as the increase in vehicle-kilometer course there is a significant change in the value of water in the oil brake. It should be noted, however, that measurement of the boiling temperature is more accurate method of determining the quality of brake fluid than the method for the determination of the percentage of 
water. This is due to the fact of greater sensitivity of this parameter to change the chemical composition of the coolant during the kilometre mileage of the vehicle. Despite its importance the research on the boiling temperature of the brake fluid is however very uncommon [17].

The ability to change the frequency of replacement of brake fluid, depending on the intensity of use of the vehicle has been shown. In vehicles with low mileage without placing an excessive burden on the braking system there is a possibility to extend the life of the brake fluid usage [5].

Monitoring of selected parameters of the brake fluid and its replacement at the right time ensures not only the correct functioning of the braking system, but contributes to the elimination of a failure of the braking system and thus increases the safety of road users.

\section{Acknowledgements}

This work was carried out in partnership between University of Life Sciences in Lublin and University of Žilina, as well as Lublin University of Technology.

\section{REFERENCES}

1. Beran E., Janik R. and Biskupski A. Evaluation of poly(alkylene glycol)s (PAG) and modification of their chemical structure for use as lubricating base oils. Przemysł Chemiczny, 82(8-9), 2003, 555-558.

2. Burdzik R. and Konieczny Ł. Application of vibroacoustic methods for monitoring and control of comfort and safety of passenger cars. Solid State Phenomena, 210, 2014, 20-25.

3. Bzura P. Lubricity-based estimation of the changes in the brake fluid quality. Journal of KONES Powertrain and Transport, 14(2), 2007, 75-80.

4. Caban J., Droździel P., Barta D. and Liščák Š. Vehicle tire pressure monitoring systems. Diagnostyka, 15(3), 2014, 11-14.

5. Caban J., Marczuk A., Vrabel J. and Śarkan B. Studies on operational wear of glycol-based brake fluid. Przemysł Chemiczny, 94(10), 2015, 1802-1806.

6. El-Garhy A.M., El-Sheikh G.A. and El-Saify M.H. Fuzzy life-extending control of anti-lock braking system. Ain Shams Engineering Journal, 4, 2013, 735-751.

7. Ellison A.B. Greaves S.P. and Bliemer C.J. Driver behaviour profiles for road safety analysis. Acci- dent Analysis and Prevention, 76, 2015, 118-132.

8. Elvik R., Kolbenstvedt M., Elvebakk B., Hervik A. and Bræin L. Costs and benefits to Sweden of Swedish road safety research. Accident Analysis and Prevention, 41, 2009, 387-392.

9. Gardyński L. and Lonkwic P. Testing polymer rollers memory in the context of passenger lift car comfort. Journal of Vibroengineering, 16(1), 2014, 225-230.

10. Garrett T.K., Newton K. and Steeds W. The motor vehicle. Reed Educational and Professional Publishing Ltd., Oxford 2001.

11. Indira V., Vasanthakumari R., Jegadeeshwaran R. and Sugumaran V. Determination of minimum sample size for fault diagnosis of automobile hydraulic brake system using power analysis. Engineering Science and Technology, an International Journal, 18, 2015, 59-69.

12. Jachowicz T. and Gajdoš I. Effect of natural ageing on some properties of oxybiodegrading agent-containing polypropylene products. Przemysl Chemiczny, 93(11), /2014, 1983-1985.

13. Jarašūnienè A. and Batarlienė N. Lithuanian road safety solutions based on intelligent transport systems. Transport, 28(1), 2013, 97-107.

14. Jegadeeshwaran R. and Sugumaran V. Fault diagnosis of automobile hydraulic brake system using statistical features and support vector machines. Mechanical Systems and Signal Processing, 5253, 2015, 436-446.

15. Johlitz M. On the representation of ageing phenomena. Journal of Adhesion, 88(7), 2012, 620-648.

16. Jun J. Potential crash exposure measures based on GPS-observed driving behavior activity metrics. The Georgia Institute of Technology, 2006.

17. Lee K. Numerical prediction of brake fluid temperature rise during braking and heat saoking. SAE Technical Paper Series, 1999-01-0483, 1999.

18. Marczuk A., Misztal W., Słowik T., Piekarski W., Bojanowska M. and Jackowska I. Chemical determinants of the use of recycled vehicle components. Przemysl Chemiczny, 94(10), 2015, 1867-1871.

19. Mensing F., Bideaux E., Trigui R., Ribet J. and Jeanneret B. Eco-driving: An economic or ecologic driving style? Transportation Research Part C, 38, 2014, 110-121.

20. Michalski R. and Wierzbicki S. An analysis of degradation of vehicles in operation. Eksploatacja i Niezawodnosc - Maintenance And Reliability, 40(1), 2008, 30-32.

21. Narodowy Program Bezpieczeństwa Ruchu Drogowego 2013-2020 ,KRBRD - materiał na posiedzenie plenarne KRBRD w dniu 08.01.2013.

22. Pavlov A.V., Kudelnikova S.P. and Vicharev A.N. On the corrosion resistance of half-metallic com- 
posite brake pads for railroad cars. Journal of Friction and Wear, 36(2), 2015, 123-126.

23. Rievaj V. and Hudák A. The road transport and safety. 11-th International congress on automotive and transport engineering, Brasov, Romania, 2010, 187-192.

24. Sawase K. and Sano Y. Application of active yaw control to vehicle dynamics by utilizing driving/ breaking force. SAE of Japan Review, 20, 1999, 289-295.

25. Sergienko V.P., Tseluev M.Y., Kolesnikov V.I., Sychev A.P., Savonchik V.A. and Yanuchkovskii, V.I. Studying thermal state of friction pairs of multidisc brake. Journal of Friction and Wear, 34(6), 2013, 421-428.

26. Shen Y., Hermans E., Bao Q., Brijs T. and Wets G. Road safety development in Europe: A decade of changes (2001-2010). Accident Analysis and Prevention, 60, 2013, 85-94.
27. Skrucany T. and Gnap J. The effect of the crosswinds on the stability of the moving vehicles. 6th International Scientific Conference on Dynamic of Civil Engineering and Transport Structures and Wind Engineering. Applied Mechanics and Materials, 617, 2014, 296-301.

28. Skrucany T., Šarkan B. and Gnap J. Influence of aerodynamic trailer devices on drag reduction measured in a wind tunnel. Eksploatacja i Niezawodnosc-Maintenance And Reliability, 18(1), 2016, 151-154.

29. Uniform provisions concerning the approval of vehicles of categories $\mathrm{M}, \mathrm{N}$ and $\mathrm{O}$ with regard to braking. UN ECE, Regulation 31.

30. Walczak M., Pieniak D. and Zwierzchowski M. The tribological characteristics of SiC particle reinforced aluminium composites. Archives of Civil and Mechanical Engineering, 15(1), 2015, 116-123. 